\title{
Crítica ou conversa? Youtubers e a crítica cinematográfica contemporânea
}

\author{
Glaucia Davino \\ Universidade Presbiteriana Mackenzie, Brasil \\ Victor Henrique Cruz Russo \\ Universidade Presbiteriana Mackenzie, Brasil
}

\begin{abstract}
The sprouting of the cinema is a recent historical episode (little more than a century) and it became an entertainment mass phenomenon that impacted our culture and society. In the beginning, since movies became product, quickly texts on this subject were included on magazines, although in a not profound way, with accented informative function. Writers (critics) used to report/tell the events/stories and made indications to the spectators, but without focusing on artistic appreciation. When movies became more consistent cultural industry art, entertainment and product, the critical became an important link point between production and spectators. Since then other styles of text had been developed: analytical, opinative, ideological, advertising, etc. The "Cahiers du Cinema" magazine (France, 1951- now) was one of main landmarks for cinematographic critical, as a new glance, according to the expressions of the society and the technologies of the time. Currently, even so the language of the cinema (matrix of the audiovisual) is expanded (diverse screens and products) until nowadays, movies continue to be one of the forceful forms to tell histories (mass and cultural niche spectators) and the critic continues to be one of the links (films and spectator). In digital culture time we are accomplices of the sprouting of other vectors for movie critical. Lovers movies started in their own Youtube Channels to criticizes films according to their expressions, to the contemporary technologies and to the society surround him/her. In that way, the canonical format by the traditional press is put in check.
\end{abstract}

Keywords: Movies, Critics, New Critics Formats, Youtubers, Digital Culture

\section{Escritores - especialistas-mediadores em seu contexto}

Em 1963, Godard ${ }^{1}$ falou, em entrevista, sobre o que pensava a respeito dos críticos de seus filmes:

Eu os tenho em mais alta conta do que a maioria das pessoas. Provavelmente porque já fui um crítico e eu disse um monte de coisas ruins. Eu fui cruel e maldoso com muita gente. Apesar de minhas opiniões serem as mesmas, quando leio críticas negativas, o importante para mim é a discussão que toma lugar. Se é boa ou ruim não é importante para mim. [...] Seja justa ou injusta, eu não me importo (...) Eu acho que as críticas genéricas são sempre pessoais. Quando eles dizem algo ruim, estão tentando atingir a pessoa (...). Mas isso não importa. Quando você é um crítico, você fica irritado e, no outro dia, passou (Chalais, 1963; Grifo nosso. Tradução automática do Youtube)
Naquela época, a crítica cinematográfica era essencialmente escrita (impressa), o discernimento do ofício e o posicionamento do profissional eram os recursos para orientar e despertar ou não o interesse do público, principalmente nos jornais diários.

Ainda nos anos 60, o movimento cinéfilo e cineclubista, que já existia desde os anos 20 , se acentuou, elevando o cinema a se constituir específica atividade cultural, que se notorizou pela mobilização principalmente de jovens inquietos com o potencial dessa mídia, num mundo (estamos nos limitando ao ocidente) em reconstrução pós-guerra. 0 cinema, com alcance intercontinental, já era a mídia de grande massa que mobilizava a comunicação, a informação, abordando dramas e situações de lugares distantes, próximos ou íntimos, na modalidade entretenimento ficcional, documental, jornalístico e mesmo experimental, com uma historia consolidada, mas não engessada. Ao contrário, o surgimento de novos equipamentos, tecnologicamente mais faceis de usar, com maior mobilidade, o domínio da linguagem e da técnica, deram o impulso para as novas cinematografias e estilos que iam surgindo.

A cinefilia foi ponto fortíssimo para compreender os diversos lugares da crítica cinematográfica. Caracterizada por não limitar-se à apreciação dos filmes, se tratava de um ambiente cultural, que envolvia tanto os momentos de projeção, como os de discussão, de registros fotográficos, de produção de textos, críticas e debates. Enquanto discutiam os filmes, também os analisavam, emitiam opiniões, Ihes atribuíam valores estéticos e artísticos, condizentes com seu tempo, tecnologias e respectivos impactos na história corrente do cinema. Essas atividades, espalhadas por vários países, foram de certa forma, restritas a pessoas que faziam parte de um nicho mais intelectualizado e que vieram dar forma às revistas especializadas, dedicadas a se aprofundarem no tema. Esse tipo de revista se multiplicou. Em destaque, as francesas Cahiers du cinema, seguida da Positif e Cinéthique, das americanas Screen, Sequence, Sight \& Sound, Film Culure e Artforum, as inglesas Screen, Sequence, Sight and Sound e Movie (Gomes, 2006), não necessariamente nessa ordem, cronologicamente falando. Algumas destas publicações permaneceram como referenciais de textos de qualidade na análise da obra cinematográfica até hoje.

A crítica de cinema ganhou a mídia televisiva pelo marcante, famoso e provocativo programa dos críticos americanos Siskel e Ebert a partir de 75 e que, em 2008, foi substituído por outro apresentador, com novo formato ${ }^{2}$. Segundo o próprio Ebert, o programa deixara de falar sobre o que era essencial do cinema, para se tornar um programa de entretenimento sobre 
cinema e não mais crítico. Essa mudança deu origem ao programa "At the movie" (Reuters, 2008). Por terem a TV como mídia, a crítica de cinema que faziam tinha alcance massivo, penetrando nas vidas, no centro das salas dos lares, nas atenções das pessoas, incluindo o carisma que a presença física e sincera dos apresentadores na tela.

A indústria do cinema, no entanto, não era representada pelas novas cinematografias, por essa cinefilia e/ou publicações críticas. Havia também publicações mais populares sobre cinema, com foco dobrado sobre a descrição das obras de maneira mais sintética, ou ranqueamento dos filmes, notícias e tablóides com a vida ou intrigas entre atores, atrizes e cineastas, não propriamente refletindo sobre a potencialidade estético-histórica dos filmes. No Brasil, de modo geral, as revistas especializadas atendiam fortemente ao mercado relacionado com a industria norteamericana, como a Scena Muda (1921-1955) e Cinelândia $(1953-1970)$. Os textos mais reflexivos eram escritos por intelectuais imersos na cultura cinéfila e foram publicados em colunas de jornais.

O sistema de exibição dos filmes nas salas de cinema, como acontece ainda hoje, funciona com contratos em que se garante a circulação de filmes. Finalizada a temporada daquelas exibições, outros filmes entravam em cartaz. As fitas de acetato, exibidas, já desgastadas e cujo título não era mais novidade, não mais voltavam para as salas, algumas eram arquivadas por suas produtoras, em cinematecas ou pelos detentores de seus direitos e outras descartadas. Como ideal de conservação de uma obra, preservava-se o negativo: se possível intacto, era guardado em condições climáticas próprias. Hoje, o acesso a qualquer filme (novo ou antigo) pode ser realizado, resumidamente, através de um comando digital. Quanto ao espectador de cinema de película, caso perdesse a oportunidade de assistir o que havia passado, não a teria mais. Sobrava, então para ele, a possibilidade de ler as críticas, resenhas e ensaios produzidos pelos autores especialistas, nas mídias impressas oficiais. Essa observação significa que muitos dos filmes foram conhecidos apenas a partir da leitura dessas críticas e não, necessariamente, por sua projeção.

A possibilidade de reprogramação de filmes antigos foi feita com a telecinagem e sua distribuição pelas TVs de diversos países, como o Brasil. Lembremos que uma geração teve a oportunidade de conhecer os filmes "velhos" dos anos 40 e 50, em "Sessão da Tarde"3, como lembrou o roteirista e diretor Rubens Rewald (Davino e Cole, 2006).

Muitas obras consideradas importantes ou que provocaram o público foram assistidas apenas em alguns países. Dessa forma, a circulação desses jornais e revistas especializadas por diversos países também eram valiosas. Muitos dos filmes produzidos, sabemos, foram perdidos, descartados, queimados ou reciclados. O conhecimento sobre alguns títulos do cinema foi possível apenas através do resultado de pesquisas históricas nas publicações, tanto de livros como de periódicos, encontrados em bibliotecas e outros sitios, i.e., apenas o que se publicou sobre esses filmes é que nos informam sobre sua existência.

Não podemos deixar de considerar os aspectos comerciais que envolviam as relações da crítica (imprensa) com a industria de cinema. Dessa forma, não faltam exemplos de críticos que eram remunerados para a escrita de uma crítica positiva, para o sucesso de bilheteria dos lançamentos, além de outras ações de marketing. Hollywood foi exemplo dinâmico de ações de marketing.

A crítica cinematográfica, paralelamente, se desenvolveu nesses contextos, e permaneceu na forma impressa, mesmo com estilos e propósitos diversificados, do final do séc. XIX até o final do XX, quando a digitalização passa a fazer parte do cotidiano social, no Brasil.

Bergala (1996) descreveu o que era um crítico de cinema: alguém que se considerasse qualificado e aceito como tal, segundo um consenso (coletivo, com quem ele se comunica), mas que seu trabalho somente é crítico se ele imprimir valores, i.e., sua avaliação precisa ser baseada em provas analíticas (não teóricas) da obra, segundo a visão e repertório de seu autor e de seus leitores. A crítica não é neutra. O público acaba por escolher os textos dos autores de que "gosta" de ler. Esse público, em torno do crítico escolhido, é aquele que compartilha gostos, visão de cinema, de arte, semelhantes e se identifica. Dessa forma, já se sentem seguros por receberem recomendação, análises, curiosidades ou dicas para que o próprio espectador filtre as fitas a serem degustadas. Gostos, como disse Bourdieu (2007), estão associados a valores simbólicos, que distinguem, classificam, aproximam e/ou afastam as pessoas que consomem os bens culturais. Isso significa que estilos de crítica, de filmes e de público se distinguem por meio das escolhas dentro dos respectivos repertórios culturais.

O movimento cinéfilo, das décadas de 60 e parte dos 70, fez parte da cultura dos Novos Cinemas no mundo. Na França, o carro chefe, a Nouvelle Vague, e no Brasil, o Cinema Novo, com o nome de Glauber Rocha simbolizando esse momento. Glauber e outros diretores ultrapassavam 0 ato de produzir filmes, pois não trabalhavam idustrialmente, e contribuíam com a reflexão sobre a cinematografia mundial e brasileira, escrevendo sobre a arte cinematográfica e a sociedade. Grandes debates foram travados entre textos e opiniões desses cineastas. ${ }^{4}$ Segundo Maurício Caleiro,

(...) a geração cinemanovista, nos anos 70, agora sob o lema "mercado é cultura", fazia as pazes com o público que não tivera na década anterior, a pretensão da revista Filme Cultura de se tornar a Cahiers du Cinèma tupiniquim, fazia com que, (...), a crítica brasileira voltasse não apenas a torcer sistematicamente o nariz - então mais empinado do que nunca - ao cinema nativo, mas a recusar desdenhosamente o debate que, com frequência, a reação dos cineastas às críticas recebidas queria deflagrar. $(2011,6)$ 
Uma das personalidades ${ }^{5}$ que deve ser destacada no cenário da crítica de cinema, no Brasil, foi Paulo Emílio Salles Gomes, que escrevia sobre cinema para os jornais, um dos fundadores do curso de cinema na Universidade de São Paulo e mentor de seus alunos, atuando em várias frentes, incluindo a Cinemateca Brasileira. Paulo Emílio deixou um significativo legado. Suas críticas eram

Densas, aprofundadas e muito bem escritas, suas críticas cumprem funções que deveriam ser a de qualquer escrito sobre arte: aproximar leitor e obra, iluminar seus desvãos, interpretar sem impor certezas. E, acima de tudo, contextualizar, pois a obra não se dá num vácuo social e, se não pode ser reduzida à conjuntura social, leva os traços desta em sua estrutura [...] Acercando-se da obra com cuidado, vendo-a por ângulos diversos, respeitando-a como enigma colocado em desafio ao espectador [...] Caso raro de crítico que, ao colocar em ação seus dotes interpretativos, coloca-se à altura da obra-prima que tem diante de si. (Estadão Conteúdo - Cultura, 2016)

Escrevia sobre o cinema estrangeiro e o nacional, mas foi pivô da consciência da nossa realidade, da nossa cinematografia e da crítica de cinema (Zuin, 2012).

Compartilhava com outros autores e/ou cineastas a visão de um cinema que dizia e se mostrava como o de um país subdesenvolvido.

\begin{abstract}
"Nesse percurso, Paulo Emílio se preocupou com uma análise nacionalista da produção de cinema nacional.... Há, porém, um fator diferenciado nessa ação: o nacionalismo de Paulo Emílio não era ufanista. "Ao contrário, era crítico, sempre tentando apreender de que forma o contexto ao qual o País está submetido influencia o cinema local." Para o crítico, a relação com o estrangeiro era válida, mas não poderia ser condição primária, já que o conhecimento era superficial, segundo Xavier." (Siqueira, 2017)
\end{abstract}

Alguns alunos de Paulo Emílio deram continuidade a esse tipo de atuação, produzindo textos tanto no universo acadêmico, onde se podia fazer profundas análises, como participavam ativamente das discussões políticas e culturais que envolviam a arte cinematográfica, através de textos.

\section{Por que falar desse período e de seus agentes}

Embora a crítica de cinema tenha iniciado muito antes, logo de sua invenção, quando “(...) a então chamada crítica era um mistura de reportagem que descrevia o evento em termos factuais e de resenha que aconselhava o leitor sobre o valor do filme" (GOMES, 2006;.2), iniciamos nosso artigo revendo a década de 60. A importância em abordar esse período está na herança das modalidades críticas e na força simbólica do que se considera, ainda hoje, o seu significado e importância.

Como vimos, o cinema tomou conta do ambiente cultural naquele período e a crítica criou matrizes, ou seja, para quem estuda cinema e estuda a crítica cinematográfica, tem como forte referência aquele tipo de jornalismo crítico, mais denso. As revistas acabaram gerando escolas de estilos críticos ao adotarem peculiaridades no processo de análise, da contextualização, dos aspectos a serem valorizados e do formato de contrução textual. Por exemplo,

(...) a revista Cahiers du Cinema, essencialmente formada por críticosrealizadores, representou, ao longo de seu percurso como publicação destinada à crítica de cinema, uma luta permanente entre, por um lado, a afirmação de um gosto e de uma estética, predominante nos anos 50 até o início dos anos 60, de submeter os filmes a certa análise por tema, por autor e gênero. (Serge Toubiana, apud Gomes, 2011)

Ao longo do tempo, a crítica de cinema impressa foi tornando-se mais enxuta, com menos espaços para reflexões ou provocações e hoje, como decorrência das mudanças da cultura digital, com a multiplicação de plataformas midiáticas, de comunicação, temos um cenário bastante diferente, diversificado. O público é formado por grupos distintos e passa por experiências diferentes diante do cinema. O conhecimento sobre a linguagem, tecnologias e, até mesmo, o fazer fílmico, etc. estão ao alcance de todos. Mesmo assim, o impasse entre os que consideram a crítica aprofundada a verdadeira crítica e outras formas sintéticas está posto.

Também podemos atribuir à critica e seu autor, com resguardo da visão e tecnologias da época, a possibilidade, mesmo que frágil, de ser um veículo do registro da história. Ao escrever, ele produz material que traz experiências de um período, tanto do ponto de vista de criação, do sistema de produção, da repercussão e a perspectiva da própria crítica. Objeto de estudos e investigações, esses textos tornaram-se documentos históricos dessa arte.

Para Godard, a

[...] crítica não é uma criação artística. Será sempre inferior. $75 \%$ dos críticos estão nesse trabalho temporariamente.... por isso são sempre amargos e tristes frente àqueles que eles honram e os que eles depreciam.

... ser crítico é uma boa experiência, um bom treinamento...Me ensinou a não ter a visão limitada (Chalais, $1963^{6}$ )

Então, podemos sumariamente notar que, sem entrar nos méritos jornalisticos, o trabalho do crítico constituiu, até um certo período, a mediação:

a) na orientação para os espectadores (identificados com determinados críticos e respectivo estilo de escrita);

b) na possibilidade de fortalecer uma cultura cinéfila (onde o filme não é o fim único);

c) na promoção de vendas e

d) na produção de documentos históricos. 


\section{A crítica de arte}

(...) Envolve interpretação, julgamento, avaliação e gosto. A crítica de arte nesse sentido específico surge no século XVIII, num ambiente caracterizado pelos salões literários e artísticos, acompanhando as exposições periódicas, o surgimento de um público e o desenvolvimento da imprensa. (Enciclopedia Itau Cultural, grifo nosso, 2017)

Conforme nos mostra a Enciclopédia do Itau Cultural, foi o advento de uma nova midia, a imprensa, que permitiu a conformação sócio-cultural para a iniciação da crítica de arte, i.e., um meio que além de registrar foi capaz de disseminar em grande escala e além território físico para os potenciais leitores e entusiastas. Assim, a atividade que se iniciou abrangia a valoração da arte sobre o olhar especializado e crítico, fazendo surgir diferentes linhas de pensamento alinhadas aos ideais dos grupos que as seguiam.

A crítica contemporânea de cinema, no Brasil, herdou dessa cultura cinéfila ocidental, desse período mencionado, algumas condutas analíticas, relfexivas, de estruturação textual, das informações e valoração artística. Os críticos brasileiros se serviram do repertório e da cultura cinematográfica (ocidental) para escrevêlas na conjunção de suas próprias sensibilidades.

O forte movimento intelectual e crítico cinematográfico das décadas anteriores ainda são balizadores das nossas críticas, principalmente daqueles que conhecem o cinema e sua história em profundidade, dos profissionais que vivenciaram aquelas experiências e são atuantes até os dias de hoje.

\section{Informação, acesso e mediação}

Mesmo o cinema sendo uma arte da reprodutibilidade técnica, como bem afirmou Benjamim (2018), era um produto que não poderia ser adquirido e levado para os lares, ninguém possuia rolos de filmes em suas prateleiras, como possuiam os discos, que portavam as músicas, e os livros, que portavam as histórias e outros conhecimentos na forma de texto. A efemeridade da TV também não permitia a posse do filme ou do programa. Ela oferecia ao público um cardápio de programas diversificados, incluindo filmes, amarrados à grade horária e não dava para escolher o que e quando assistir, sequer interromper o fluxo da exibição. Então, tinha-se como veículo de crítica a imprensa, o telejornal e algum programa voltado ao tema, na singularidade de cada mídia, mas com o princípio de quem falava ser um expert produzindo e veiculando o conhecimento para todos os outros.

A proeza da posse e/ou portabilidade de filmes vai surgir apenas no meio dos nos anos 80, no Brasil, com o homevídeo (fitas e, posteriormente DVDs que poderiam ser comprados ou alugados e levados para assistir em casa, no momento em que se desejasse. A consequência foi grande, a oferta de filmes se transformou, i.e. se multiplicou dentre filmes antigos, novos lançamentos que haviam sido exibidos e os não exibidos nas salas de cinema, filmes importados, telefilmes, filmes nacionais, séries, documentários, infantis, etc. O formato deu mais autonomia ao espectador que não precisaria ir ao cinema, nem esperar que a TV lhe oferecesse algum filme de seu gosto, no horário desejado. Essa mudança foi, com certeza, uma primeira em que a mobilidade da mídia permitia que o audiovisual (escolhido) pudesse ir para dentro de casa. Hoje, quase tudo, pelas telas dos computadores, pode ser levado para "dentro de casa" ou em qualquer lugar que estejamos. Até compras de objetos, vestuário, alimentos, podem ser feitos a partir de casa. Não mais o consumidor, mas sim o fornecedor é que se move. No caso das mídias, a materialidade está nos objetos de acesso, não nos filmes em si. Mas, o videocassete ainda era um objeto a ser retirado e devolvido no prazo (se não, multa!).

De certa forma, vemos que as janelas/telas dos filmes começam a se expandir: cinema, TV e vídeo e, consequentemente, os tipos de críticas. Não são todos os espectadores de filmes que cultivam cinefilia crítica, mas sim a de entretenimento, a de assistir a alguns filmes e/ou uma "coleção" como atração, como produto de gosto pessoal. Além do mais, a leitura de críticas pode não fazer parte de seus rituais culturais. Há consumidor que assiste a novos títulos quando é influenciado por alguém que comenta, não necessariamente vai a busca da critica especializada.

Com o videocassete, ao mesmo tempo em que houve aumento de público por título, houve também a pulverização do que alguns cinéfilos mais puristas considerariam "filmes comerciais" (sem valores artísticos). De qualquer maneira, o mercado ampliou bastante trazendo filmes que jamais teriam sido assistidos aqui no Brazil ou em outras partes do mundo, incluindo filmes do início da história do cinema, como os mudos. Esse mercado, de certa forma, fez com que o costume de assistir filmes se democratizasse um pouco mais. A crítica também se diversificou atendendo a essa demanda. Novas publicações periódicas, como revistas e sessões culturais da imprensa, surgiam ou se segmentavam de acordo com o tipo de produto: filmes lançados nos cinemas ou as novidades em vídeo, muitas vezes financiadas pelas distribuidoras e produtoras com intuito de divulgação. Para os cinéfilos mais afoitos, as revistas SET, Revista de Cinema, Sci-Fi News, Sci-Fi Cinema, ajudavam a dar foco àqueles que buscavam fontes de informação, no Brasil. Podemos ressaltar que, muitas vezes, ficava a cargo dos atendentes das locadoras fazerem as indicações de filmes para seus clientes, ou seja, a mediação sobre conteúdo, estilo, gênero, ano etc. Alugar filmes semanalmente (principalmente para os fins de semana) passou a ser um hábito. Diferentemente da TV e do cinema, a escolha das fitas, que poderiam ser mais de uma simultaneamente, não dependiam apenas das características cinematográficas, mas a outras externas, como preço, promoção, indicação etária, gostos pessoais, da família, dos amigos e do atendente da locadora. Os comentários, opiniões e impressões espontâneos e pessoais ficavam no âmbito particular, entre pessoas (amigos, colegas, familia, etc.). 


\section{Rompendo papéis - cinefilia digital}

Assim como o cinema não sumiu com o advento de tantas outras tecnologias, a paixão por ele também não. Pessoas de todas as idades, com destaque para os jovens, são fãs de filmes, conhecem seus títulos, diretores, atores, buscam estar informados constantemente e se identificam com uns e outros estilos. Há aqueles que cultuam e apreciam filmes dos tempos áureos do cinema de hollywood, das vanguardas, das origens da história do cinema, querem saber tudo e muito mais sobre a produção de cinema, outros "não perdem uma estréia" nas grandes telas $^{7}$ (salas de cinema) e também, uma minoria, se arrisca a buscar filmes mais raros, i.e., fora do grande circuito, como os de países do leste europeu, Africa, etc., mais acessíveis em festivais, importantes focos para os críticos.

Com a conexão em redes, a mediação digital foi se arraigando na nossa cultura, fazendo parte de nosso cotidiano. Primeiro, com os computadores individuais e posteriormente com os dispositivos móveis (smartphones, smartwatches,, etc.). Com mais plataformas de linguagem de disseminação de conhecimentos, opiniões e ideias, a crítica de cinema passou a se dividir - ou se multiplicar - entre a "impressa" oficial e o espaço digital. Dos grandes portais, sob o comando de empresas de comunicação aos blogs, vlogs, a comunicação ou periódicos no formato para internet possibilitaram qualquer pessoa criar sites (mais complexos) e blogs (de mais fácil operação, mais baratos ou gratuitos) para expor suas ideias, vender seus produtos e ou serviços, etc.

No cyberespaço, conhecimentos individuais compartilhados estão ao alcance de qualquer outra pessoa no mundo, demovendo o lugar de exclusividade do crítico especializado. Muitos cinéfilos, estudiosos e interessados passaram a escrever sobre filmes, sem a necessidade de aprovação ou de chancela das mídias de comunicação oficiais e/ou diplomação acadêmica para o exercício da crítica pública. A fala do opinador/ crítico já poderia ser partilhada, não apenas no seu grupo de amigos e de convívio, mas com pessoas desconhecidas (muitas). Seus textos, imagens e hiperlinks poderiam ser encontrados a partir de um simples toque de tecla, comandado por algorítimos. $\mathrm{Na}$ maioria dos casos, os leitores também poderiam deixar suas opiniões, a favor, contra ou complementar àquilo que o autor escrevia, "postava", em espaço próprio.

O site Cinema em Cena ${ }^{8}$, criado por Pablo Villaça, é um exemplo do surgimento dos sites especializados no Brasil, pois foi um dos primeiros, na área de cinema. Hoje, o site se desdobra dentre as plataformas de linguagens, incluindo, certamente, o Youtube.

\section{Youtube - Janela audiovisual}

A plataforma de vídeo online Youtube, iniciada em 2005, nos EUA, e em 2010, no Brasil, foi uma das mais impactantes plataformas de interconexão entre usuários.
O site revolucionou a forma como as pessoas se comunicam e se tornou um dos principais serviços do Google ${ }^{9}$. (...) Na sua edição de 13 de novembro de 2006, a revista norte-americana Time, elegeu o YouTube a melhor invenção do ano por, entre outros motivos, "criar uma nova forma para milhões de pessoas se entreterem, se educarem e se chocarem de uma maneira como nunca foi vista. (Brito, 2015).

De uma plataforma digital para a realização de uploads no formato de vídeos online, se transformou num forte veículo de filmes, séries, curtas, reprodução de eventos, DIY e outros produtos, mas também uma janela de aproximação e de interconexão entre entidades, sociedade, pessoas, atuantes ou seguidoras. Além de podermos assistir a filmes (produções de cinema) e programas de TV (televisão), todo tipo de assunto pode ser encontrado na plataforma, através de canais de empresas e individuais - muitos com o nome do autor, que se convencionou chamar de Youtubers. $O$ que caracteriza um youtuber não é apenas a postagem de vídeos num espaço dele, mas desse espaço se constituir num canal com identidade (nicho e assuntos), produzir com determinada frequência, ter canal aberto a todos que se interessarem, ser protagonista e autor (voz e/ou imagem), oferecer espaço para a participação (moderada pelo formato da plataforma) dos seguidores e hiperlinks para outros conteúdos. Sua estrutura é modular. Cada canal está sob a responsabilidade de seu "proprietário" (empresas ou pessoas físicas). E sua produção é seriada, com as mesmas características em cada capítulo da série.

No Brasil, os canais de crítica de cinema têm crescido, não dependem mais dos meios editoriais das empresas de comunicação. Segue a esse crescimento, o número de seguidores que fidelizam ou não com aquele canal. Há canais de críticos já legitimados por outras mídias oficiais (atuam em rádios, escrevem, etc. e têm seu canal), pelo currículo ou pela comunidade cinematográfica (formação e experiência profissional, inclusive como crítico "nativo analógico") e os canais criados, simplesmente, por fãs de cinema que além de fazerem o que gostam: assistir a filmes e falar sobre cinema - podem se tornar famosos e até mesmo monetizar essas atividades.

O fenômeno da fama em decorrência dos programas, ações e produções das personalidades do cinema, TV, jornalismo, publicidade das mídias tradicionais não desapareceram, na realidade o fenômeno se expandiu para as plataformas de linguagem, na Internet. As personalidades, dotadas de determinado capital cultural (Bordieu, 1998; 28), idolatradas e seguidas pelos fãs, acabam influenciando suas vidas cotidianas e, mais, seu consumo.

An influencer, or opinion leader, is a person who is regarded by a group or by other people as having expertise or knowledge on a particular subject (Assael 1984; Weiman 1991).

O conceito de influenciador social, que não é inédito, volta com força na cultura digital, sob a visão do mercado, os "digital influencers", como evidenciou a Meio \& Mensagem ${ }^{10}$ 
A figura do digital influencer viu sua importância crescer em especial na última década. Para indivíduos da Geração Z (...), YouTubers, Blogueiros e Instagramers tem tão ou mais influência que personalidades da TV, Cinema, ou de outros nichos do entretenimento. (...) Os influenciadores, em conjunto com fatores sociais, culturais e de motivação pessoal, estão entre os principais elementos capazes de direcionar uma decisão de compra e uma maior aproximação entre uma marca e o seu público-alvo. (Marques, 2017)

O Youtube, sendo audiovisual, se tornou uma das vias mais fortes para a formação de um influenciador, i.e., um líder capaz de conduzir a opinião e, principalmente, o consumo. Além da facilidade de acesso, a participação dos usuários, a curta duração, o formato "entretenimento', dentre outras qualidades, há os algoritimos, que relacionam as atividades dos usuários e os aproximam de conteúdos afins e que favorecem e justificam as transformações desse meio para a elaboração crítica dos filmes.

\section{Como se escolhe filmes para assistir}

Tantos estímulos audiovisuais, tantos títulos e lançamentos de grandes produções de arrastar multidões, com efeitos incríveis, tantos festivais, tantos filmes do circuito independente e tantos canais de acesso aos filmes que, será que precisamos de um guia? Onde encontrar referências?

\begin{abstract}
... , pessoas que gravam críticas para o YouTube deixaram de ser apenas críticos de cinema, eles se tornaram também youtubers capazes de influenciar digitalmente milhares, e, em alguns casos, até milhões de pessoas. Ainda que críticos de jornal também tinham o poder de mudar a opinião das pessoas sobre os filmes, o influenciador digital tem uma proximidade muito maior de seu público. Com inúmeras opções de canais no YouTube sobre cinema, os usuários se inscrevem naqueles em que eles realmente gostam dos vídeos. Isso faz com que o público só siga o crítico que ele realmente confia. (Russo e Davino, 2018; 09)
\end{abstract}

As críticas, no formato audiovisual, apresentam os youtubers como pessoas, com cara, trejeitos, voz e defeitos. Edição, o cenário, a duração, o enquadramento, o direcionamento do olhar para o espectador, a roupa, etc. aproximam o público, como que se fosse presencial, daí uma das características intrínsecas desse formato. Diferentemente, as críticas escritas, em que o leitor tem acesso apenas às abstrações do texto, que lhe exige atenção visual, a transcodificação dos signos escritos para o verbal (mentalmente) e o controle auditivo, para não se distrair, seu acesso visual à identidade do autor é nula.

A narrativa youtuber pega emprestado, principalmente, algumas matrizes dos programas de apresentador, conhecidos como "programas de auditório", típicos da TV. Então, verificamos que, acima das opiniões, da influência que terão sobre o espectador daquele filme, a escolha do canal resulta de uma escolha pela personagem alí construída. O jeito do locutor é mais importante do que o conteúdo, resumindo. O espaço de interação/opinião, fica aberto para manifestações de discordância ou de diálogos, nem sempre com a intervenção do dono do canal.. O "quem" predomina sobre o "o quê". Se alguém é fã de um youtuber, então tudo que ali aparece deve ser considerado como valor social e de entretenimento.

\section{Arena crítica: cinema, escrita e Youtubers}

Opiniões se embatem a respeito da crítica de arte e crítica cultural, incluindo a do próprio cinema, e refletem a diversidade das experiências, dos valores, dos veículos para os quais estão produzindo, do contexto de cada crítico. Vejamos, por exemplo, para a colunista irlandes Corey Fischer, a crítica pode enriquecer a experiência do espectador e que "Without criticism, films are devalued and the cultural importance of films and documentaries wanes " (Fischer, 2015), i.e., é o trabalho especializado do crítico que que tem o aval para provocar transformações, aperfeiçoamento da indústria e dos próprios critérios de avaliação do público. Na opinião de Simran Hans, do The Observer Culture, em entrevista que questiona a crítica frente à "era da opinião" (The Observer, 2018), ela demonstra que, ao crítico, cabe levantar questões não tão evidentes nesses filmes. Por esse detalhamento especializado, muitas vezes os profissionais são taxados de elitista ou propagandistas (Hans, 2018). Como escritores, ambos críticos exemplificados acima, defendem a importância que se configura como balizadora para que a indústria, o público e o cinema como entretenimento se mantenham ativos, assim como sua própria atividade.

Já, quanto aos cineastas, o indiscutível diretor Werner Herzog, diretor alemão e incisivamente autoral deixa, em 2011, sua opinião à Revista Cult, (Simões, 2011)

Nunca fui especialmente influenciado pela crítica de cinema. Em parte porque recebi péssimas críticas para alguns de meus melhores filmes, assim como boas críticas que achei um tanto deslocadas. Sempre foi claro para mim que uma boa crítica não melhora um filme, assim como uma crítica ruim tampouco torna o filme ruim. Ao longo de minha carreira, eu quase não li críticas. Para mim, são sempre como um acontecimento que pouco tem a ver comigo. Em termos gerais, hoje em dia vejo que a crítica de cinema está em extinção, pois o discurso sério vem sendo substituído pelo noticiário sobre celebridades. Muitos jornais e revistas nem têm mais críticos de cinema e quase tudo que você lê neles tem a ver com os astros de cinema. (2011, grifo nosso)

A indiferença às críticas também está presente para David Lynch, como o foi para Fellini que, ao serem indagados sobre o significado de suas opções estéticas, desprezam-nas. A postura desses cineastas contradiz a postura dos críticos acima exemplificados, como a de servir às mudanças na indústria.

Os youtubers de cinema constituem mais um ramo do trabalho crítico de filmes, mas como discutido anteriormente, seu formato, sua espontaneidade e 
informalidade textual, próprio da comunicação oral, dão um tom diferenciado, que atrai o público mais acostumado com a comunicação instantânea.

O documentário "Crítica de cinema através de uma lente" (Russo, 2018, orientado por Davino, G), colocou alguns youtubers, cujos canais se propõe como o de crítica de cinema e/ou assim são considerados por seus seguidores, para falarem sobre a validade e a legitimação da crítica contemporânea, expandida para esse canal audiovisual e assuntos que orbitam a prática da crítica.
Se há alguma dúvida a respeito do negócio, da atividade, o primeiro dado que é inegável se atribui aos de números de inscritos, demonstrados na tabela abaixo. O número de visualizações é outro indicador importantíssimo, pois é aquele que dá vida e mostra a repercussão do canal.

Os participantes youtubers, desse documentário, além de seu diretor/roteirista/editor (no início e no encerramento), são quatro brasileiros.

\begin{tabular}{|l|l|l|l|l|}
\hline Youtuber & Canal & Início & Inscritos & Visualizações \\
\hline Rolandinho & Pipocando & 2013 & 3.970 .392 & 473.363 .506 \\
\hline Joyce Pais & Cinemascope & 2011 & 15.000 & 452.608 \\
\hline Tiago Belotti & Meus 2 Centavos & 2006 & 230.152 & 41.982 .703 \\
\hline Max Valarezo & Entre Planos & 2015 & 224.701 & 10.129 .759 \\
\hline
\end{tabular}

Tabela 1: Dados coletados pela autora, em maio de 2019

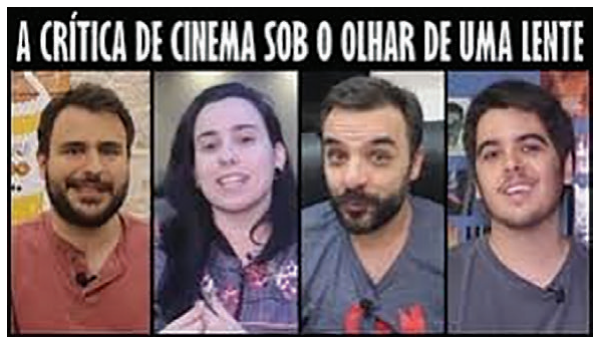

Figure 1: "Movietubers" que estão no documentário A Crítica de cinema sob o olhar de uma lente, de Victor Russo, 2018. Fonte: acervo do autor Victor Russo.

O quadro acima compara os dados de cada um dos canais. Os números não são suficientes para compreender plenamente as motivações dos interessados em ver-ouvir as críticas. Esse não é nosso foco imediato, mas sim o diálogo que permite convalidar o trabalho desses críticos, como tal. O perfil de formação, os propósitos, os conteúdos são e os aspectos formais de cada canal são bastante diversos. O que podemos denominar como comum a todos os youtubers, está relacionado principalmente à moldura da plataforma, da qual não há como escapar, que é o repositório de vídeos, com títulos individuais, podendo ser agrupados por categorias e a diagramação da página, além do uso de tela inteira como opcional.

A curadoria, no entanto, ultrapassa a crítica de filmes, em maior ou menor grau, conforme a proposta do canal. Alguns acrescentam conteúdos educativos, sobre o próprio canal, assuntos sobre eventos do cinema, cursos, análises que desvendam os recursos da linguagem cinematográfica, etc.

Nesse documentário, a unanimidade na "sentença final" sobre o papel dos youtubers críticos de cinema, como se consideram, o autor concluiu que
O que detectamos é que, a crítica escrita mantém seu espaço, mas os canais do YouTube apontam para um futuro dominante do crítico opinativo online, pois o público tem a chance de escolher o olhar e o perfil daquele com quem se identifica, diferentemente do jornalismo escrito em um veículo de oficial (Russo e Davino, 2018; 21)

\section{Conversas finais: Legitimando Movietubers}

Contemporâneos à sua época, jovens amantes de cinema fundaram revistas onde puderam estabelecer comunicação com um público, através da crítica, da teorização e da análise de filmes, nos anos 60 , como falamos no início desse artigo.

Contemporâneos à sua época, nas primeiras décadas do século $\mathrm{XXI}$, os amantes do cinema puderam abrir diálogos com um público massivo, através da criação de seus próprios canais de vídeo.

Para os youtubers entrevistados no documentário "A crítica do cinema sob o olhar de uma lente" (op. cit), o aumento de interesse pelo novo formato não eliminaria, mas colocaria em xeque a crítica canônica escrita, herdeira dos movimentos cinematográficos mundiais. Para o jornalista e crítico de cinema, José Geraldo Couto,

A crítica profissional de cinema defronta-se hoje com novos problemas, oriundos sobretudo do declínio econômico (e de influência) dos veículos impressos, em paralelo à extraordinária proliferação de vozes e canais de expressão propiciada pela internet. Essa situação coloca em xeque o papel do crítico como formador de opinião, curador de repertório e influenciador do gosto do público, recolocando, sobre novas bases, questões antigas como: para que serve a crítica? A quem ela se destina? Quem está habilitado ou legitimado a fazê-la? Como fazer frente às pressões do mercado de entretenimento e do gosto médio (ou senso comum) sem fazer da crítica uma pregação para convertidos ou um diálogo entre iniciados? (Couto, 2018; 26) 
É comum, nas culturas, a valorização da preservação da "tradição" (herança cultural), um saber fazer alinhado, aceito pela comunidade e repetido por gerações. Isso designa, comumente, a necessidade das permanências que, às vezes nos espantam. O novo, o diferente, começa a motivar incômodo e rejeição, por isso as mudanças acabam arrastando consigo o universo o anterior. Não que as mudanças sejam sempre positivas ou sempre negativas.

Muitos dos youtubers, não apenas de cinema, são considerados influenciadores digitais, pois são capazes de mobilizar hordas de fãs e/ou até mesmo haters ${ }^{11}$. Fãs que, por adoração e identificação, seguem opiniões, sugestões e realizações dessas personalidades. Como num reality show, ao vivo, e com formato mais compacto, dispondo seus verdadeiros rostos e falando com a câmera (como se estivesse olhando para a pessoa que assiste), o youtuber ganhou parte do tempo de entretenimento e, porque não, de aquisição de conhecimento, antes dedicados à TV, ao cinema e à leitura. Não que o youtube os substitua, ele apenas se tornou mais um canal de acesso, no com as características verbovisual, de fácil compreensão, onde o modo particular da persona youtuber é a principal atração. Como os famosos atores da TV, o público torce e cuida dessas personalidades.

Como investigadores sobre o cinema e, nesse trabalho, sobre a crítica, o incômodo está presente. No site cultural do jornal Britânico The Guardian, foi discutida a crítica de arte (incluindo cinema) no atual contexto, em que se testemunha o decaimento do número de críticos nos jornais e o ascende número de críticos, na web. "(...) an insurgent type of criticism - breezy, immediate and intimate - on the internet." (Donaldson, 2018)

Parece que, como a arte e a cultura, a questão da crítica pelo youtube ser ou não crítica de cinema, não passa necessariamente pela questão da mídia em si, mas sim pela legitimação daquele que a conduz. Estão aí os fake news para comprovar que filtros são necessários, de alguma maneira.

O que os youtubers fazem não são necessariamente críticas de cinema, no sentido canônico. Mais do que informar, propõem um diálogo com o público, com a obra, com o cinema e com aquilo que está acontecendo, no imediatismo do momento. São mediadores, mas são também atores. Não apenas transmitem o que têm a dizer, mas usam seus corpos, voz, cenário para fazer isso, elaboram e seguem um roteiro.

Nossas considerações finais apontam para a necessidade de um novo olhar para a produção youtuber da área de cinema.

A disputa por um pódio de crítica de cinema não é coerente. Os fatos mostram que há uma geração de youtubers dedicada ao cinema. Ontologicamente, há produção de conteúdos diferenciados, em relação ao universo da cinefilia. Então, ao invés das categorias genéricas "youtubers" ou "críticos de cinema", que não dão conta dessa complexidade, cabe dizer que há a construção de um novo lugar e um novo nome para esses produtores de conteúdo, os Movietubers. Seus trabalhos vão além da crítica. Têm a capacidade de se expor e, através de uma comunicação dinâmica, em frente à câmera, tratar de assuntos caros ao público, como numa conversa proporcionando, em alguns casos, diversão, ou o despertar da curiosidade.

\section{Notas Finais}

1 Jean-Luc Godard, franco-suiço, é considerado um dos maiores diretores de cinema no mundo ocidental, pois foi um dos fundadores da Nouvelle Vague francesa (movimento cinematográfico, que mudou paradigmas), juntamente com Truffaut, Chabrol, Rohmer e Rivette, e depois continuou com produções irreverentes. O início de sua carreira, no entanto foi como crítico, escrevendo para o "La Gazette du Cinema" e a "Cahiers du Cinéma" uma das mais importantes revistas de crítica de cinema, até hoje.

2 "Siskel \& Ebert" foi um famoso programa televisual de crítica de filmes cinematográficos, conduzido por dois críticos que conversavam sobre os filmes de forma provocativa, a partir de vasto repertório e domínio sobre cinema. Entre 1975 e 1982, era intitulado "Sneak Previews", depois "Siskel \& Ebert \& the Movies". Dentre outras transformações, como ocorrem nos programas televisivos, "At the Movies with Ebert and Roeper" e, por fim "At the Movies", a partir de 2008.

3 Sessão da Tarde é o nome de um programa diário (segunda à sexta-feira) vespertino, da TV Globo (empresa de telecomunicação brasileira). É um programa em que oferece filmes não inéditos, para um público jovem. É possível verificar uma lista (não sabemos se completa) de filmes da primeira fase publicada no site Filmow por Silva: https://filmow.com/listas/ primeira-fase-da-sessao-da-tarde-de-1974-a-1989-153137/

4 Intelectual brasileiro, com atuação na cultura, foi um dos fundadores do curso de cinema na USP, da Cinemateca Brasileira onde atuou incisivamente em favor da preservação de filmes.

${ }^{5}$ Alex Viany é outro nome importante sobre a revisão do cinema brasileiro, até então, que teve grande influência no pensamento dos diretores cinemanovistas.

${ }^{6}$ Entrevista de Jean-Luc Godard a François Chalais, quando do lançamento de "o desprezo" (Mépris), The Talk of the town, 1963.

${ }^{7}$ Estamos denominando filmes de grandes telas, os filmes blockbusters com primoroso tratamento de imagens e sons e efeitos especiais visuais e sonoros feitos para impactar sensorialmente. Esses filmes, ao serem assistidos em outra plataforma, que não a sala de cinema, perdem o impacto estésico que somente a grande tela proporcionaria.

${ }^{8}$ Cinema em Cena - Portal http://cinemaemcena.com.br/

9 O YouTube foi criado por ex-funcionário do Pay Pal e depois adquirido pela empresa do Google.

${ }^{10}$ A revista Meio \& Mensagem é uma revista brasileira da área da publicidade e propaganda, criada em 1976. Portal Meio e Mensagem: https://www.meioemensagem.com.br/

${ }^{11}$ A palavra hater (em ingles), traduzido por "aqueles que odeiam", é atualmente o termo utilizado para designar aqueles que.

\section{Referências}

\section{Livros}

Bourdieu, Pierre. Escritos de educação. Petrópolis: Vozes, 1998

\section{Livros traduzidos com indicação autor}

Benjamin, Walter. 2018. A obra de arte na era de sua reprodutibilidade técnica. Traduzido por Gabriel Valladão Silva. 
Rizzato, henrique (2018). "Documentário mostra os bastidores da crítica de cinema no youtube", in Cinemação - Portal. https://cinemacao.com/2018/11/26/documentariomostra-os-bastidores-da-critica-de-cinema-no-youtube/

\section{Livro eletrónico e textos em linha}

Estadão Conteúdo - CULTURA. "O legado crítico de cinema Paulo Emilio Salles Gomes", 01/09/16. https://istoe. com.br/o-legado-critico-de-cinema-paulo-emilio-salles/.

Zuin, João Carlos Soares (2012) "Paulo Emílio Salles Gomes: a compreensão da realidade brasileira através da crítica de cinema" in Sociedade e Estado, vol.27 no.2 Brasília May/Aug. http://dx.doi.org/10.1590/ S0102-69922012000200002

\section{Artigos em revistas e jornais}

Basuroy, Suman, Chatterjee, Subimal S. And Ravid, Abraham (2003). "How Critical are Critical Reviews? The Box Office Effects of Film Critics, Star Power, and Budgets" in Journal of Marketing; Volume: 67 issue: 4, page(s): 103-117. Issue published: October 1, 2003. https://doi. org/10.1509/jmkg.67.4.103.18692 e https://journals. sagepub.com/doi/full/10.1509/jmkg.67.4.103.18692\#_i1

Bergala, Alain (1996). "Critique/théorie : l'évaluation et la preuve" in Cinémas Revue d'études cinématographiques, vol. 6, $\mathrm{n}^{\circ}$ 2-3, Spring: 29-44. https://www.erudit.org/en/ journals/cine/1996-v6-n2-3-cine1500561/1000970ar/

Donaldson, Sarah (2018). "Do we still need critics in this age of opinion?" in The Observer Culture, The Guardian, sun 18 nov 2018, https://www.theguardian.com/ culture/2018/nov/18/do-we-still-need-critics-susannahclapp-simran-hans.

Silva, Moises. "Primeira Fase da Sessão da Tarde de 1974 á 1989" in Filmow - Portal: https://filmow.com/listas/ primeira-fase-da-sessao-da-tarde-de-1974-a-1989-I53137/

Simões, Eduardo (2011). "Werner Herzog: 'A crítica de cinema está em extinção'” in Cult - Sessão Entrevistas. 01 de abril de 2011. https://revistacult.uol.com.br/home/ werner-herzog-a-critica-de-cinema-acabou/

Siqueira, André. (2017) "'Paulo Emílio unia crítica e conjuntura do País', diz Ismail Xavier", Jornal da USP, editorial Cultura. Outubro. Disponível em: https://jornal. usp.br/?p=121046

\section{Video / filme / audiovisual}

A Crítica De Cinema Sob O Olhar De Uma Lente (documentário), direção Victor Russo, 2018, in Canal "2 Centavos". Upload realizado em: 21/11/2018, https:// www.youtube.com/watch?time_continue $=1271 \& \mathrm{v}=\mathrm{M} 7 \mathrm{~N}-$ 02JA2C.

A Crítica De Cinema Sob O Olhar De Uma Lente, direção Victor Russo, 2018. Upload realizado em: 19/11/2018, Orientação Profa. Dra. Glaucia Davino.

Chalais (1963). Entrevista Com Jean-Luc Godard a François, apresentado no prograga Cinepanorama, em 1964.- Disponível em: https://youtu.be/w3U2hDVZ940 Canal Filipe Gonçalves. Youtube, 2011.

Davino, Glaucia e Cole, Ariane (2006). Entrevista realizada com o Roteirista Rubens Rewald, para o projeto "Histórias de Roteiristas: as Histórias de Rubens Rewald". DVD autorado.

\section{Tese / Dissertação}

Andrade, Sâmea Larisse. (2006). Os novos caminhos da crítica de cinema no Brasil: Analisando a seção de cinema da revista Veja. Monografia, UniCEUB.

Gomes, Regina (2006). Crítica de cinema: história e influência sobre o leitor. Crítica Cultural, volume 1, número 2, jul/dez. http://portaldeperiodicos.unisul.br/index. php/Critica_Cultural/article/viewFile/93/103.https://www. youtube.com/watch?v=RawrmsIN4WE

Russo, Victor e Davino, G. (orientador) (2018). A crítica de cinema sob o olhar de uma lente. Trabalho de conclusão de curso de jornalismo. Universidade Presbiteriana Mackenzie.

\section{Conferência, Comunicação apresentada em Congresso}

Brito, Edivaldo (2015). "YouTube faz 10 anos: descubra qual foi o primeiro vídeo do site" in Tech Tudo (site). https:// www.techtudo.com.br/noticias/noticia/2015/02/youtubefaz-10-anos-descubra-qual-foi-o-primeiro-video-do-site. html.

Caleiro, Maurício (2011). "A crítica de cinema como agente historiográfico e a história canônica do cinema brasileiro" in VIII Encontro Nacional de História da Mídia, Guarapuava (PR): Unicentro. http://www.ufrgs. br/alcar/encontros-nacionais-1/encontros-nacionais/8oencontro- 2011 - 1 /artigos/A $\% 20$ critica $\% 20$ de $\% 20$ cinema $\% 20$ como\%20agente $\% 20$ historiografico $\% 20$ e\%20a\%20historia\%20canonica $\% 20$ do $\% 20$ cinema $\% 20$ brasileiro.pdf/at_download/file.

Couto, José Geraldo (2018). "Crítica de cinema - Novos desafios" in Caderno de resumos | $2^{\circ}$ Simpósio de Crítica de Mídia | Como fazer para criticar?, Universidade de São Paulo chrome-extension://cbnaodkpfinfiipjblikofhlhlcickei/ $\mathrm{src} /$ pdfviewer/web/viewer.html?file=https://repositorio.ufsc. $\mathrm{br} / \mathrm{bits}$ tream/handle/123456789/191709/CADERNO\%20 DE\%20RESUMOS.pdf?sequence=1\&isAllowed=y.

Enciclopedia Itau Cultural (2017) "Artigo da Sessão Termos e Conceitos: Crítica de Arte". http://enciclopedia. itaucultural.org.br/termo3178/critica-de-arte

REUTERS (2008). " Crítico de cinema Roger Ebert será substituído na TV dos EUA". O Globo Cultura, 22/07/2008. https://oglobo.globo.com/cultura/critico-de-cinema-rogerebert-sera-substituido-na-tv-dos-eua-3608160.

\section{Sites e canais do Youtube}

Cinema em Cena: https://www.cinemaemcena.com.br. Cinemascope, canal do Youtube, de Joyce Pais (2011 - atual) https://www.youtube.com/user/cinemascopesite/ playlists.

Cineset: http://www.cineset.com.br.

Entre Planos, canal do Youtube de Max Valarezo (2015 - atual) https://www.youtube.com/channel/UCZq_ CYXRoRjKqidapMPujaQ/featured.

Larioscine:https://www.youtube.com/channel/ UC1N2Z_775guXajvxsk72uYg.

Meus 2 Centavos, canal do Youtube, de Tiago Belotti (2006 - atual) https://www.youtube.com/user/tiagobelotti/ about.

Pipocando, canal do Youtube de Bruno Bock e Rolandinho (2013 - atual) https://www.youtube.com/user/ pipocandovideos. 